\title{
Enzymatic Production of Bio-Diesel from Waste Cooking Oil Using Lipase
}

\author{
Sulaiman Al-Zuhair*
}

Chemical \& Petroleum Engineering Department, U.A.E. University, 17555 Al-Ain, UAE

\begin{abstract}
The applications of lipase immobilized on ceramic beads and entrapped in sol-gel matrix, in the production of bio-diesel from waste cooking oil, are compared to that of free lipase. Experimental determination of the effect of molar equivalent of methanol, to moles of ester bond in the triglyceride, on the rate of the enzymatic trans-esterification was experimentally determined. It was found that for the same weight of lipase used, the production of bio-diesel was much higher using lipase immobilized on ceramic beads in comparison to that using lipase entrapped in sol-gel and in free form. Substrates inhibition effect was observed in all cases, which agrees with previous results found in literature. The optimum methanol:oil molar ratio was found to be 0.87 for immobilized lipase from yeast source, $C$. antartica and 1.00 for free lipase from the same yeast source and immobilized lipase from bacterial source, $P$. cepacia. On the other hand, it was shown that biodieasel can be produced in considerable amounts, with yield reaching $40 \%$, in absence of organic solvent using immobilized lipase, from P. cepacia, on ceramic beads. The results of this study can be used to determine the kinetics parameters of mathematical models which describe the system.
\end{abstract}

\section{INTRODUCTION}

The high cost of bio-diesel, compared to petroleum-based diesel, is a major barrier to its commercialization. It has been reported that $60-90 \%$ of bio-diesel cost arises from the cost of the feedstock oil [1]. Therefore, the use of waste cooking oil (WCO) should greatly reduce the cost of bio-diesel. In addition, production of bio-diesel from WCO is considered an important step in reducing and recycling waste. A fresh vegetable oil and its waste differ significantly in water and free fatty acids (FFAs) contents, which are around $2000 \mathrm{ppm}$ and $10-15 \%$, respectively [1-2]. This renders conventional alkaline catalyst unsuitable, and limits the use of chemical catalysts to the slower acidic ones [2].

When a biocatalyst (enzyme), namely lipase, is used the problem facing chemical catalysts are readily avoided. Lipase is capable of converting all the FFAs contained in WCO to their respective fatty acids methyl esters (FAMEs). It is important however to immobilize lipase, for practical applications, to be able to recover and reuse it repeatedly $[3,4]$.

Traditional method for lipase immobilization has largely relied upon its physical adsorption onto solid surfaces, due to its ease and absence of expensive and toxic chemicals. On the other hand, poor adsorption of enzyme results in its leaching off the support surface, which favours other means of enzyme immobilization such as covalent bonding, entrapment and encapsulation. It is possible to strengthen the attachment between the water-soluble enzyme and the waterinsoluble surfaces by using multifunctional agents that are bifunctional in nature and have low molecular weight, such as glutaraldehyde [5]. The author of this article has studied the kinetics of lipase adsorption and a temperature dependence correlation for the amount of adsorbed lipase activity and that present in the supernatant solution was determined

*Address correspondence to this author at the Chemical \& Petroleum Engineering Department, U.A.E. University, 17555 Al-Ain, UAE;

E-mail: S.Alzuhair@uaeu.ac.ae
[5]. On the other hand, the immobilized lipase by entrapment within a polymer matrix is much more stable than physically adsorbed lipase [6], and unlike the covalent bonding [5]. Entrapment of lipase in an inorganic polymer matrix, which is based on sol-gel process, is well documented [7].

Although lipase is not affected by the high content of FFAs in WCO, the high water content remains a problem. Water is needed for expression of enzyme activity; however, large water contents favors oil hydrolysis, rather than transesterification [8-9]. In order to overcome this problem, the use of lipase in immobilized forms, adsorbed on ceramic beads and encapsulated in sol-gel, is investigated as a countermeasure. In addition, the applicability of lipases extracted from different microbial sources, such as yeast and bacteria, is also tested in this study.

Immobilized enzymes are known to give better transformation rates in the organic media. This in fact involves merely dispersal of enzyme over a large surface. As both enzyme and ceramic remain insoluble under non-aqueous conditions, the preparation as such serves as immobilized preparation. This is frequently known to enhance catalytic performance and it was shown that immobilized lipase from $P$. cepacia performed better than free enzyme (under the same conditions) [10]. The main advantage of immobilization of an enzyme however, is that an expensive enzyme can be repeatedly used. Therefore, the ability to use the immobilized enzyme repeatedly is actually the factor that determines its effectiveness. Due to the negative effect caused by byproduct glycerol adsorbed on the surface of the immobilized lipase, a loss in activity is inevitable with repeated uses. However, the immobilized lipase retained more then $70 \%$ of its initial activity even after more than ten cycles. This was found when using different lipases immobilized on different solid surfaces, such as Novozyme 435 (C. Antarctica lipase immobilized on acrylic resin) [11] and $P$. fluorescens lipase immobilized on toyonite [12]. Organic solvents, such as $n$ hexane, are usually used to dissolve the by-product glycerol, which clogs the active sites of the immobilized lipase. How- 
ever, the addition of organic solvent has several drawbacks, such as, diluting reactants, adding mass transfer resistances and requiring additional solvent recovery unit. In this study, the prospect of bio-diesel production in solvent-free system is examined, and compared to that in $n$-hexane solvent.

\section{REACTION MECHANISM}

The mechanismic steps were explained thoroughly in our previous paper [13], and were represented by Eqs (1-6):

$$
\begin{aligned}
& \mathrm{E}+\mathrm{S} \underset{\mathrm{k}_{-1}}{\stackrel{\mathrm{k}_{1}}{\leftrightarrow} \mathrm{E} . S} \\
& \mathrm{E} . \mathrm{S} \leftrightarrow \mathrm{E} \cdot \mathrm{Ac} \cdot \mathrm{G} \\
& \text { E.Ac.G } \underset{\mathrm{k}_{-2}}{\stackrel{\mathrm{k}_{2}}{\leftrightarrow}} \mathrm{E} \cdot \mathrm{Ac}+\mathrm{G} \\
& \text { E.Ac }+\underset{\mathrm{k}_{-3}}{\mathrm{~A}} \stackrel{\mathrm{k}_{3}}{\leftrightarrow} \mathrm{E} \cdot \mathrm{Ac} \cdot \mathrm{A} \\
& \text { E.Ac.A } \underset{\leftrightarrow}{\leftrightarrow} \mathrm{E} \cdot \mathrm{Bd} \\
& \text { E.Bd } \underset{\mathrm{k}_{-4}}{\leftrightarrow} \mathrm{E}+\mathrm{Bd}
\end{aligned}
$$

Where, $\mathrm{E}$ is the enzyme concentration, $\mathrm{k}_{1}$ and $\mathrm{k}_{-1}, \mathrm{k}_{2}$ and $\mathrm{k}_{-2}$ and $\mathrm{k}_{3}$ and $\mathrm{k}_{-3}$ are the rate constants for the reversible formation of enzyme-substrate complex, E.S, acylated enzymeglycerol moiety complex, E.Ac.G, acylated enzyme-alcohol complex, E.Ac.A, respectively and $\mathrm{k}_{4}$ and $\mathrm{k}_{-4}$ are the rate constants for the product formation and enzyme regeneration. To account for the inhibition by alcohol A, competitive inhibition was assumed when an alcohol molecule reacts with the enzyme directly to produce a dead-end enzymealcohol complex (E.A). And to account for the inhibition by the substrate $\mathrm{S}$, competitive inhibition was also assumed when a substrate molecule reacts with the acylated enzyme to produce another dead-end complex, namely, acylated enzyme-substrate complex (E-Ac.S). The two competitive inhibition reactions mentioned above were presented by Eqs (7) and (8), respectively:

$$
\begin{aligned}
& \mathrm{E}+\mathrm{A} \underset{\mathrm{k}_{-5}}{\stackrel{\mathrm{k}_{5}}{\leftrightarrow}} \mathrm{E} . \mathrm{A} \\
& \mathrm{E} . \mathrm{Ac}+\mathrm{S} \underset{\mathrm{k}_{-6}}{\stackrel{\mathrm{k}_{6}}{\leftrightarrow} \mathrm{E} . A c . S}
\end{aligned}
$$

Where, $\mathrm{k}_{5}$ and $\mathrm{k}_{-5}$ and $\mathrm{k}_{6}$ and $\mathrm{k}_{-6}$ are the rate constants for the reversible formation of dead-end complexes, enzymealcohol, E.S, and acylated enzyme-substrate, respectively.

\section{EXPERIMENTAL SET-UP}

\section{Chemicals}

Palm oil was purchased from local market, and used to prepare the WCO. All other chemicals and lipases were purchased from Sigma-Aldrich. Lipase from yeast source, namely Candida Antarctica, was used in this study free, immobilized on ceramic beads and encapsulated in sol-gel matrix, with claimed activities of $1 \mathrm{kU} \mathrm{g}^{-1}, 2 \mathrm{kU} \mathrm{g}^{-1}$ and $1.5 \mathrm{kU}$ $\mathrm{g}^{-1}$, respectively. In addition, lipase from bacteria, Pseudomonas cepacia, immobilized on ceramic beads, with claimed activity of $1.5 \mathrm{kU} \mathrm{g}^{-1}$, was also used.

\section{Waste Oil Preparation}

Inconsistency would an inevitable problem should real WCO was used. Therefore, and in order to ensure consistency, WCO was simulated experimentally by heating $1 \mathrm{~L}$ of palm oil on a hot plate (Stuart, U.K.), set at its maximum heating power for two hours. The oil was allowed to cool to room temperature and then $5 \mathrm{ml}$ of water (around $5000 \mathrm{ppm}$ ) was added. The sample was then shelved for two weeks before being used. Fresh WCO samples were prepared every two weeks.

\section{Enzyme Solution}

Free and immobilized $C$. Antarctica lipase solutions were prepared by adding $0.02 \mathrm{~g}$ of from lipase to $1 \mathrm{ml}$ distilled water. On the other hand, immobilized $P$. cepacia lipase solution was prepared by adding $0.1 \mathrm{~g}$ of lipase to $1 \mathrm{ml}$ of distilled water. When immobilized lipases were used, they were soaked in water for 30 minutes, prior to being used. This step was found experimentally essential to activate the enzymes. However, when soluble enzyme was used, the soaking step was not required.

\section{Bio-Diesel Production in $\boldsymbol{n}$-Hexane Solvent System Using C. Antarctica Lipase}

The experiment took place in a specially designed $150 \mathrm{ml}$ capacity jacketed reactor cell. The cell was kept on a magnetic stirrer (Velp Scientifica, Italy) to facilitate the agitation of the mixture. Water from a temperature controlled water bath (Grant Instruments, UK) circulated through the jacket and was set to maintain the temperature of the reaction media constant at $45^{\circ} \mathrm{C}$. The temperature used was that presented in the literature to be the optimum $[8,9]$ and an agitation speed was chosen to provide suitable mixing without affecting the activity of the enzyme. In this part, the working volume at the beginning of each experiment was $50 \mathrm{ml}$, consisting of $5 \mathrm{~g}$ of WCO, different volumes of methanol, in the range of 0.4 to $0.8 \mathrm{ml}$ (correspond to 0.57 to 1.14 molar equivalents of ester bonds in the triglyceride chain), and $n$ hexane to make up the total volume. The cell was covered tightly throughout the progress of the experiments to prevent evaporation. After thermal equilibrium was ensured, $1 \mathrm{ml}$ of enzyme solution containing $0.4 \% \mathrm{~g}$ of $C$. Antarctica lipase per $\mathrm{g}$ oil, was added to initiate the reaction. Free lipase as well as immobilized on ceramic beads on encapsulated in sol-gel matrix were used in this part. At suitable intervals, $1.5 \mathrm{ml}$ samples were withdrawn into a capped vial, immediately immersed in boiling water for at least 5 minutes to denature the enzyme and stop the reaction, and then sent for analysis.

\section{Bio-Diesel Production in Solvent-Free System Using Im- mobilized $P$. cepacia Lipase}

The same experimental procedure explained in the previous section was followed. However, in this part the initial reaction mixture consists of $50 \mathrm{~g}$ of WCO and different volumes of methanol, in the range of 4.3 to $8.3 \mathrm{ml}$ (correspond to 0.58 to 1.14 molar equivalents of ester bonds in the triglyceride chain). No solvent was used in this part. After thermal equilibrium was ensured, $1 \mathrm{ml}$ of enzyme solution containing $0.2 \% \mathrm{~g}$ immobilized lipase per g oil, was added to initiate the reaction. 


\section{FAMEs Analysis}

The amounts of FAMEs in the samples were determined using Gas Chromatograph (Chrompack CP 9001, Holland). Using a pipette, $0.5 \mathrm{ml}$ was extracted from the withdrawn sample vial and placed in a $10 \mathrm{ml}$ volumetric flask. $2 \mathrm{ml}$ of Internal Standard (Fluorene $500 \mathrm{mg} / \mathrm{l}$ ) was added and the sample volume was adjusted to $10 \mathrm{ml}$ using hexane. The prepared diluted samples were then injected in a spiltless mode into the GC. The column used was Omegawax 320 capillary column (Supelco, $30 \mathrm{~m} \times 0.32 \mathrm{~mm} \times 0.25 \mu \mathrm{m}$ film thickness). Nitrogen was used as the carrier gas at $70 \mathrm{kPa}$. The heating program of the oven was $50^{\circ} \mathrm{C}$ for $2 \mathrm{~min}$, which was raised to $100{ }^{\circ} \mathrm{C}$ at heating rate $20{ }^{\circ} \mathrm{C} \mathrm{min}{ }^{-1}$, then from $100-240{ }^{\circ} \mathrm{C}$ at heating rate $10 \mathrm{C} \mathrm{min}^{-1}$ and stabilized at final temperature for $11.5 \mathrm{~min}$. The areas of the generated peaks were determined and compared with those obtained with different dilutions of known amounts of standard FAMEs, namely, oleic, linoleic, stearic and palmitic methyl esters. Standard FAMEs considered were the ones found in appreciable amounts in palm oil.

\section{RESULTS \& ANALYSIS}

\section{Bio-Diesel Production in Organic Solvent Using Free $C$. Antarctica Lipase}

The production yield of bio-diesel in $n$-hexane solvent system using different molar equivalents of methanol was investigated, and the results are shown in Figs. (1-3) for $0.4 \%$ g $C$. Antarctica lipase per g oil in free form, immobilized on ceramic beads and entrapped in sol-gel matrix, respectively.

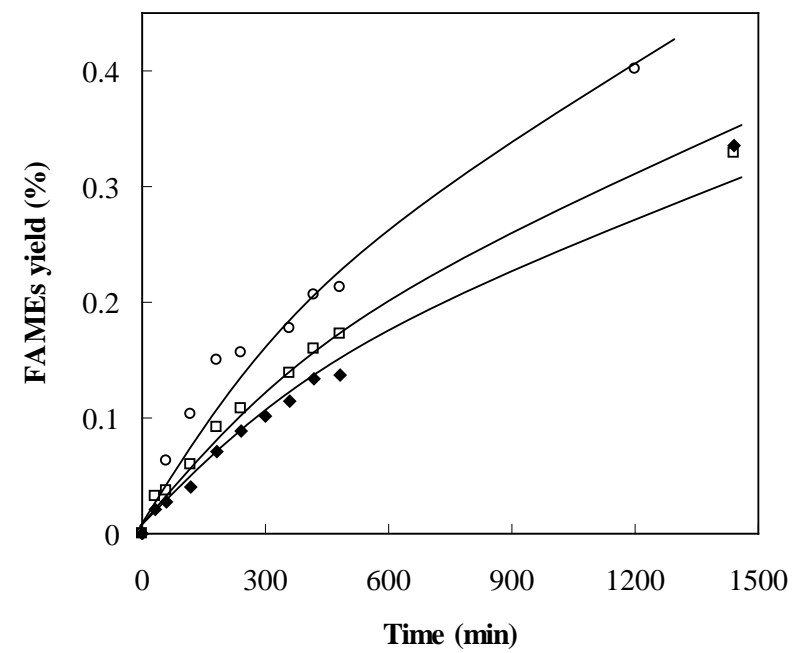

Fig. (1). Change of FAME yield with time using $0.4 \% \mathrm{~g}$ free $C$. Antarctica lipase per $g$ oil (methanol molar equivalents of $\bullet 0.58$, $\square 0.71$ and $\bigcirc 1.00)$.

To avoid congestion, the yields at methanol molar equivalents, of ester bond on the triglyceride chain, of 0.87 and 1.14 are not shown in Fig. (1) and yield at molar equivalent of 0.58 is not shown in Fig. (2). However, it was possible to show all five methanol ratios in Fig. (3) clearly. The results shown in Figs. (1-3) illustrate that when the reaction took place in $n$-hexane solvent system, the bio-diesel production yield increased linearly at the beginning, but after around $500 \mathrm{~min}$, the rate of production was slightly de- creased. However, the equilibrium yield was not reached during the course of the experiment for all three cases of lipase used, namely free, immobilized on ceramic beads and entrapped in sol-gel matrix.

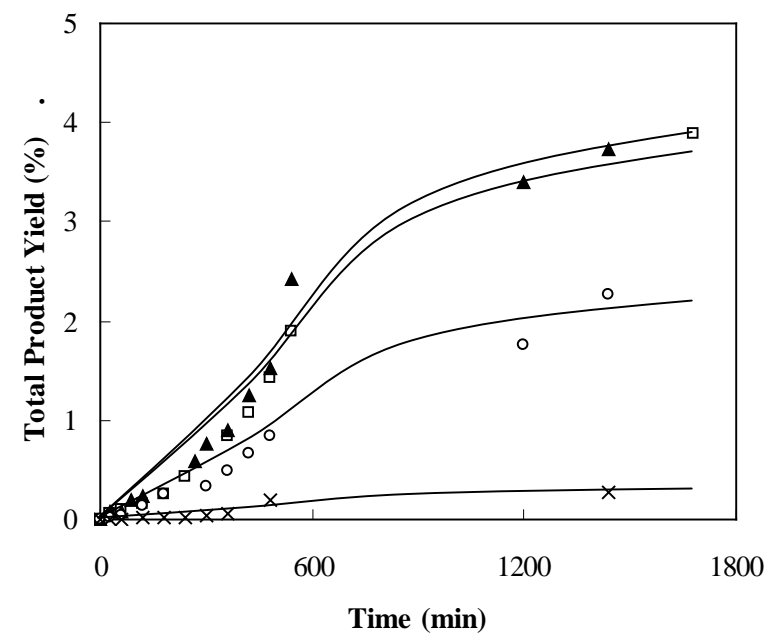

Fig. (2). Change of FAME yield with time using $0.4 \% \mathrm{~g}$ immobilized $C$. antarctica lipase on ceramic beads per $g$ oil (methanol molar equivalents of $\square 0.71, \Delta 0.86, \bigcirc 1.00$ and $x 1.14$ ).

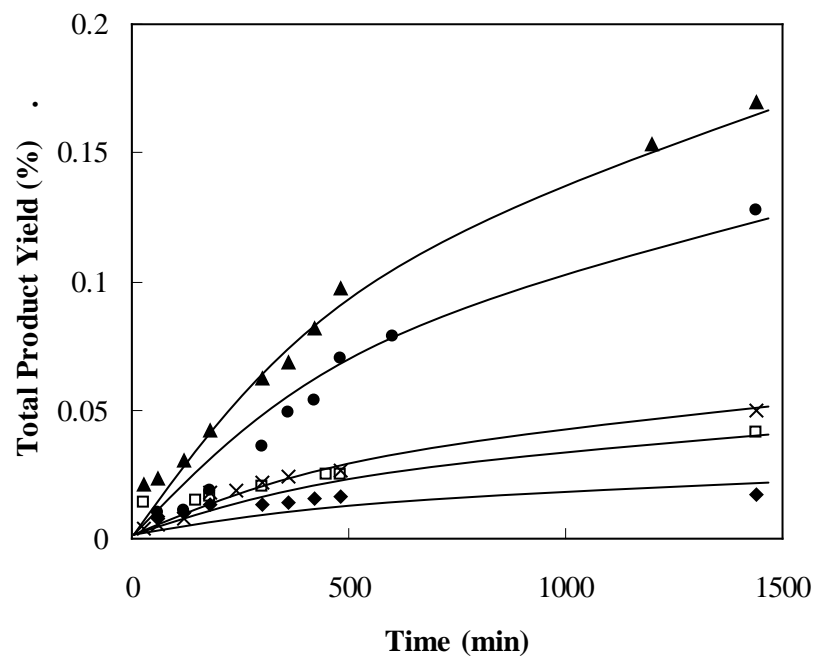

Fig. (3). Change of FAME yield with time using $0.4 \% \mathrm{~g}$ immobilized $C$. antarctica lipase in sol-gel matrix per g oil (methanol molar equivalents of $\diamond 0.58, \square 0.71, \boldsymbol{\Delta} 0.86, \bigcirc 1.00$ and $\mathrm{x} 1.14$ ).

The results in Figs. (1-3) also show that the production rate was highest when immobilized lipase on ceramic beads was used and lowest when entrapped lipase in sol-gel matrix was used. This clearly proves that lipase immobilized on ceramic beads is the most suitable for bio-diesel production from WCO. The reason for this can be attributed to the enhanced trans-esterification activity of the lipase at higher water contents by immobilization on solid surface. This was not available in other types of lipases that were clearly not suitable for use with WCO of high water content, which was used in this study. The lower yields when entrapped lipase was used, in comparison to when free lipase was used, are attributed to the mass transfer limitations. 
The initial rate of reaction at each case was determined from the slope at time zero of the straight line that best fits product concentration versus time data. The relationship between methanol amount, presented as molar equivalent of ester bonds in the triglyceride chain, and the initial reaction rate are shown in Fig. (4) The lines, appearing in the graph, are connections between the results to show the trends.

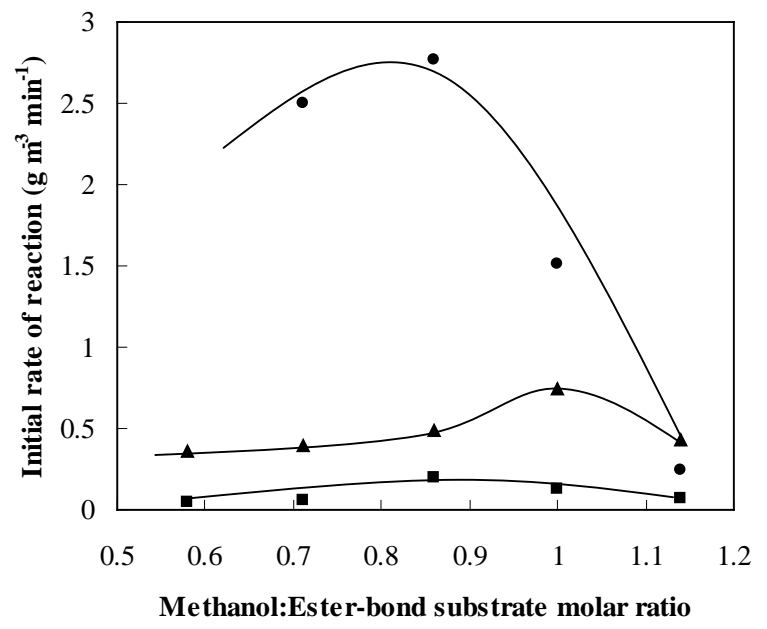

Fig. (4). Effect of methanol molar ratio on initial rate of reaction using C. Antarctica lipase, $\boldsymbol{\square}$ entrapped in sol-gel matrix, $\boldsymbol{\Delta}$ free and $\bigcirc$ immobilized on ceramic beads.

The results in Fig. (4) show that the initial rate of reaction increased with increasing methanol molar equivalent up to an optimum value and then abruptly dropped beyond that point, which indicates the presence of methanol inhibition. The optimum methanol molar value was 1.0 when soluble enzyme was used, which agrees with the results of Soumanou and Bornscheuer. [8] and Fukuda et al. [9]. However, the optimum methanol molar value was found at 0.87 when lipase used was immobilized on ceramic beads and encapsulated in sol-gel. On the other hand, as explained by AlZuhair et al. [13], the low initial rate of reaction at low amount of methanol, is partly due to the low reactant concentration, and mainly due to oil inhibition. The results in Fig. (4) show that the drop in reaction rate was steeper when methanol amount exceeded its optimum value than when oil amount exceeded its optimum. This indicates that the reaction is more inhibited by alcohol than by oil, which also agrees with previously reported results [9].

\section{Bio-Diesel Production in Solvent-Free System Using Im- mobilized $P$. cepacia Lipase on Ceramic Beads}

The results of the previous section clearly show the advantage of using immobilized lipase on ceramic beads over free lipase on entrapped lipase in sol-gel matrix for the production of bio-diesel from WCO of high water contents. Therefore in this part the more favorable immobilization form was used. It was also interesting to investigate the effect of the source of lipase, and therefore lipase from bacterial source, namely $P$. cepacia, was used in this section. In addition, due to the several disadvantages of using organic solvent, mentioned earlier, in this part, the reaction was carried out in a solvent free system. The effect of different methanol molar ratios, with respect to the ester bond in the triglyceride chain, is shown in Fig. (5) for $0.2 \%$ g enzyme per $\mathrm{g}$ oil. To avoid congestion, the production rate at methanol molar equivalent, of ester bond on the triglyceride chain, of 1.14 was not shown in Fig. (5).

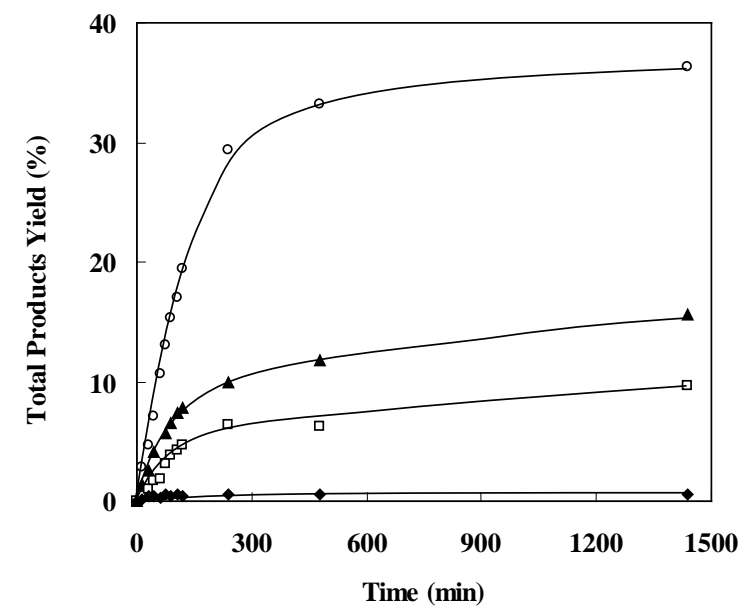

Fig. (5). Change of FAME yield with time using $0.2 \% \mathrm{~g}$ immobilized $P$. cepacia lipase per g oil (methanol molar equivalents of $\bullet$ $0.58, \square 0.73, \Delta 0.86$ and $\bigcirc 1.00)$.

The results show that the bio-diesel production yield increased linearly at the beginning, but after around $500 \mathrm{~min}$, the production rate reduced, until it reached zero and equilibrium yield was reached. In solvent free system the equilibrium yield was reached much faster than in $n$-hexane solvent system. This is due to the high production of glycerol, which was depositing on the immobilized lipase and clogging it. Unlike in the organic solvent system, in solvent-free system the produced glycerol does not dissolve. Nevertheless, it was observed that at any instant of time, the production yield in solvent free system was higher than that in $n$-hexane solvent system, which is due to substrates dilution effect in the organic solvent. In addition, the amount of enzyme used per volume of reaction medium was much higher in solvent free system. Nevertheless, the results clearly prove that immobilization of lipase favors the trans-esterification of WCO and the use of organic solvent is not required. In addition, the enzyme used in this part was from bacteria, namely $P$. cepacia, compared to the one used in the previous section, which was from yeast, namely $C$. Antarctica. This may prove that lipases from bacteria are more capable of catalyzing trans-esterification of WCO that contains high water content.

The initial rate of reaction at each case was determined and the results are shown in Fig. (6). Methanol inhibition effect was observed at methanol molar equivalent of 1.0 when immobilized lipase was used in solvent-free system. The results in Fig. (6) show that the effect of oil inhibition was more potent than in $n$-hexane solvent system, which is due to substrates dilution effect in the organic solvent.

\section{CONCLUSIONS}

The productions of bio-diesel from WCO catalyzed by immobilized lipase in solvent free system and in $n$-hexane system were investigated. It was found that immobilised 


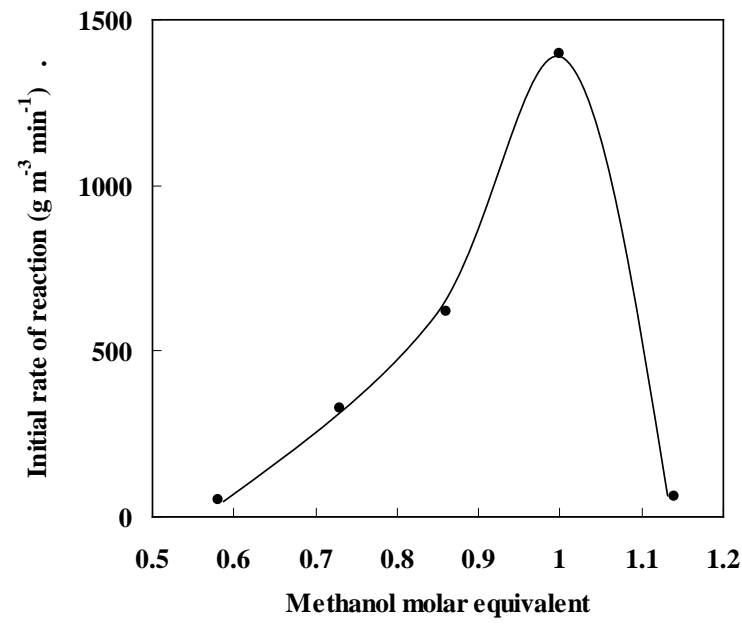

Fig. (6). Effect of amount of methanol used on initial rate of reaction using $0.2 \% \mathrm{~g}$ immobilized $P$. cepacia lipase per $\mathrm{g}$ oil.

lipase on ceramic beads were more capable of transesterifying WCO, with high water contents, to biodiesel that lipase in free or entrapped in sol-gel matix forms. The reaction was inhibited by methanol more than by oil. The inhibition effect of oil more evident in solvent free system in comparison to in $n$-hexane solvent system. The results show the equilibrium was reached much faster in solvent-free system than in $n$-hexane solvent system. However, the production yield using immobilized lipase in solvent-free system was higher than that in $n$-hexane solvent system. In addition, lipases from bacteria were found to be more competent in catalyzing the trans-esterification of WCO that contains high water content compared to lipases from yeast. The results of this study can be used to determine the kinetic parameters of a reliable dynamic model that describes the system.

\section{ACKNOWLEDGEMENTS}

The investigator would like to express his sincere appreciation to the Research Affairs at the United Arab Emirates
University for the financial support of this project under fund grant \# 01-02-7-11/07.

The investigator would also like to express his gratitude to Dr. Ali Dowaidar and Eng. Hassan Kamal for their valuable contribution to the success of this project.

\section{REFERENCES}

[1] C.C. Lai, S. Zulaikah, S.R. Vali, and Y. Ju, "Lipase-catalyzed Production of Biodiesel from Rice Bran Oil", J. Chem. Tech. Biotech., vol. 80, pp. 331-337, 2005.

[2] Y. Zhang, M.A. Dube, D.D. McLean, and M. Kates, "Biodiesel production from waste cooking oil: Economic assessment and sensitivity analysis", Bioresources Technol., vol. 90, pp. 229-240, 2003.

[3] D.S. Clark, "Can immobilization be exploited to modify enzyme activity?", TIBTECH, vol. 12, pp. 439-443, 1994.

[4] D. Cowan, "Industrial enzyme technology". TIBTECH, vol. 14, pp. 177-178, 1996

[5] M.M. Shamel, K.B. Ramachandran, M. Hasan, and S. Al-Zuhair. "Hydrolysis of Palm and Olive Oils by Immobilized Lipase Using Hollow-Fibre Reactor". Biochem. Eng. J., vol. 34, pp. 228-235, 2007

[6] W. Hartmeier, "Immobilized biocatalysts-from simple to complex systems", Trends in Biotechnol., vol. 3, pp.149-153, 1985.

[7] M.T. Reetz, "Entrapment of biocatalysts in hydrophobic sol-gel material for use in organic chemistry", Adv. Materials, vol. 9, pp. 943-954, 1997.

[8] M.M. Soumanou, and U.T. Bornscheuer, "Improvement in lipasecatalyzed synthesis of fatty acid methyl esters from sunflower oil", Enzyme Microb. Technol., vol. 33, pp. 97-103, 2003.

[9] H. Fukuda, A. Kondo and H. Noda. "Biodiesel fuel production by transesterification of oils", J. Biosci. Bioeng., vol. 9, pp. 405, 2001.

[10] S Shah, S. Sharma, M.N. Gupta. "Lipase catalyzed preparation of biodiesel from Jatropha oil in a solvent free system", Proc Biochem., in press.

[11] D. Wei, X. Yuanyuan, L. Dehua, Z. Jing. "Comparative study on lipase-catalyzed transformation of soybean oil for biodiesel production with different acyl acceptors". J. Mol. Cat. B: Enz., vol. 30, pp. 125-129, 2004.

[12] M. Iso, B. Chen, M. Eguchi, T. Kudo, S.Shrestha "Production of biodiesel fuel from triglycerides and alcohol using immobilized lipase". J. Mol. Cat. B: Enzy., vol. 16, pp, 53-58, 2001.

[13] S. Al-Zuhair, W.L. Fan, and S.J. Lim, "Proposed kinetic mechanism of the production of biodiesel from palm oil using lipase", Proc. Biochem., vol. 42, pp. 951-960, 2007. 